\title{
Estimation of liquidity risk in banking
}

\author{
Patrick Tobin Alan Brown*
}

(Received 8 August 2003; revised 19 December 2003)

\begin{abstract}
This method of modelling liquidity risk uses a "bottom-up" approach. Real bank data has been used and transformed for both ease of use and security. Identifying the degree of liquidity risk enables a bank to take action to avert problem areas overall and bring accountability to management in individual units within the institution. Critical problems identified include data availability - the set task is to identify the worst 3 days in 10,000 - and possible confounding with market risk.
\end{abstract}

\section{Contents}

\section{Introduction}

*Swinburne University of Technology, Hawthorn, Australia. mailto:ptobin@swin. edu.au

See http://anziamj.austms.org.au/V45/CTAC2003/Tobi for this article, (C) Austral. Mathematical Soc. 2004. Published June 24, 2004. ISSN 1446-8735 


\section{Data}

3 The basic model

4 Data distributions

C523

5 Correlations

C524

5.1 Correlation by amounts . . . . . . . . . . . . . C524

5.2 Correlation between number and size of withdrawals . . . C525

5.3 A model of which allows for dependence . . . . . . . C526

5.4 Degree of association . . . . . . . . . . . . . C527

5.5 Principal risk factors . . . . . . . . . . . . C527

6 Conclusion

C532

References

C533

\section{Introduction}

Banks commonly identify four specific forms of financial risk - credit risk, operational risk, market risk and liquidity risk $[1,5]$. The first three of these have been extensively studied and are commonly incorporated into existing capital allocation frameworks. Banks are exposed to a liquidity risk that a large amount of depositors' funds may be withdrawn in a short period of time. This risk is partly confounded with market risk as depositor behaviour can arise from perceptions of the market state - such as in a stock market fall. Unlike the other risk factors, no technique for modelling liquidity risk currently has wide acceptance although use of modified Value at Risk models has been suggested $[4,3]$.

Liquidity risk is a risk which must be managed as it cannot be eliminated or transferred [5]. Liquidity problems can occur in normal times as no mar- 
kets are perfectly liquid or in crisis times where the most severe outcomes can be expected. Management of liquidity in normal times can include use of carefully designed derivative instruments [3] as well as sensible practice on controlling cash flows. To guard against liquidity risk a bank must hold in reserve sufficient funds to meet all but the most extreme possibilities. The cost of holding these reserves has to be built into the price of a banking product. The liquidity risk is assessed independently for each product to avoid unintended subsidisation across products. In this analysis we examine a specific banking case and review performance on four products on offer - personal transactions, savings accounts, term deposits which are carded (those with standard interest rates offered on fixed periods) and term deposits which are non-carded (where the deposit is negotiated on an ad hoc basis). The specific task was to assess the level at which the reserves would be adequate, with a probability of $99.97 \%$, to cover the withdrawals in a week for these four retail banking products.

\section{Data}

Transaction data by amount and numbers for product and type were supplied for each day in the period October 29, 2000 to June 30, 2001, a total of 245 days (35 weeks). Pivot tables in an Excel spreadsheet were used to summarise the data by amount and number by type. The daily values for the withdrawal type were used for the initial analysis.

In a real application additional data would be used by a bank to get more accurate and reliable results. However, the data supplied is sufficient to illustrate the method.

The time series for the working days showed a regular (weekly or fortnightly) cycle, interrupted at times by the incidence of public holidays. There was some evidence of additional volumes of transactions after these holidays, and so working with weekly data smoothed out some of these irregularities. 


\section{The basic model}

Suppose that in week $t$ there are $N_{t}$ withdrawals. The total withdrawals for the week is $Z_{t}$.

We assume that each $N_{t}>0$ and $Z_{t}>0$.

The data supplied by the bank was daily for each of $N_{t}$ and $Z_{t}$ but these were amalgamated to weekly data and, after the data pruning discussed, we have the maximum $t$ is $T=35$ here. It was not possible to tell anything about individual depositors although this might be significant with major clients on some products like noncarded term deposits.

We find the average size of withdrawal each week is $Y_{t}$ where

$$
Y_{t}=\frac{Z_{t}}{N_{t}} \quad \text { or, equivalently, } \quad Z_{t}=N_{t} \times Y_{t} \quad \text { for } t=1,2, \ldots, T
$$

The data was rescaled using average values taken over the 35 week period to ensure that confidentiality is maintained. These average values were

$$
\bar{N}=\sum_{t=1}^{T} N_{t}, \quad \bar{Y}=\sum_{t=1}^{T} Y_{t}, \quad \bar{Z}=\sum_{t=1}^{T} Z_{t},
$$

so that we have the rescaled data, which we have named the mob $M_{t}$, the clip $C_{t}$ and the bag $B_{t}$ where

$$
M_{t}=\frac{N_{t}}{\bar{N}}, \quad C_{t}=\frac{Y_{t}}{\bar{Y}}, \quad B_{t}=\frac{Z_{t}}{\bar{Z}} .
$$

The basic model was applied to products, $p$, within business lines. The bag for each product $p$ at time $t$ is then $B_{p t}$. It is a bottom-up model whereas many measures used previously by banks to estimate liquidity risk have been top-down models. The aggregate for a business line $B L_{t}$ is calculated as

$$
B L_{t}=\sum_{p=1}^{k} w_{p} B_{p t}
$$


summing over the products. From this it follows that the weights, $w_{p}$, which are not disclosed, must always satisfy

$$
\sum_{p=1}^{k} w_{p}=1 .
$$

The weekly mean values were calculated. This gave rise to weekly factors with a mean of 1 , irrespective of the incidence of public holidays. The dispersion of these weekly factors was the subject of further analysis.

\section{Data distributions}

The sample moments of each distribution is readily calculated from the data. The standard deviation is the same as the coefficient of variation when the mean is 1 . The skewness and kurtosis are based on the third and fourth moments.

The Normal Power approximation [2, Chapter 4] is used to estimate the 99.97\% point of the amount distribution. This approximation to the normal distribution, $y$, for the number of bags required, $x$, is

$$
\frac{x-\mu}{\sigma}=y+\frac{\gamma}{6}\left(y^{2}-1\right)+\frac{\kappa}{24}\left(y^{3}-3 y\right)+\frac{\gamma}{6}\left(2 y^{3}-5 y\right)+\mathcal{O}\left(n^{-1.5}\right),
$$

where $\Phi(y)=1-\epsilon$ gives the normal variate in terms of its tail $\epsilon$. Here $\epsilon=0.03 \%=0.0003$ so that $\Phi(y)=0.9997=99.97 \%$. The inverse normal distribution then gives $y=3.432$. The values of the mean $\mu$, standard deviation $\sigma$, skewness $\gamma$ and kurtosis $\kappa$ from the distribution of amount data are then used to find $x$. The number of reserve bags is $x-1$.

The final term in the approximation indicates that any error can be made smaller by increasing the size of the sample data, $n$. The use of just 35 weeks of data to estimate probabilities at the 3 in 10,000 level involves a high degree 
TABLE 1: the reserves at $99.97 \%$ confidence level for the four products as well as data on the distribution moments.

$\begin{array}{llllll}\text { Product } & \text { Pers. } & \text { Savings } & \text { Carded } & \text { Noncarded } & \text { All } \\ & \text { Trans. } & \text { A/C's } & \text { Term Dep } & \text { Term Dep } & \text { Retail } \\ \text { Mean bag, } \mu & 1.000 & 1.000 & 1.000 & 1.000 & 1.000 \\ \text { Std dev'n, } \sigma & 0.096 & 0.146 & 0.259 & 0.355 & 0.150 \\ \text { Skewness, } \gamma & 0.333 & -0.488 & 1.161 & 1.468 & 0.689 \\ \text { Kurtosis, } \kappa & 6.372 & 2.086 & 1.454 & 3.573 & 1.976 \\ \text { Reserve Bags } & 1.138 & 0.692 & 1.284 & 2.397 & 0.945\end{array}$

of extrapolation as we are attempting to estimate the reserves required for the worst week in 64 years!

Consider Table 1. The high kurtosis in the amount of personal transactional withdrawal is due to an Easter effect. The term deposit withdrawals have strong positive skewness in amount due to positive skewness in their size. The overall reserve indicated for all products is less than the sum of the reserves for each individual product. This is due to less than perfect correlation for movements by all the products in the data.

\section{Correlations}

\subsection{Correlation by amounts}

The persistence of the difference in product movements should not be relied upon when extreme circumstances are being contemplated. Examine the correlation effect in detail shown in Table 2. The correlation of withdrawal amounts between products is fairly high within a week, but falls away rapidly at weekly lags 1 and 2. This indicates a propensity for high withdrawals to occur for all products at the same time. 
TABLE 2: the correlation of the withdrawal amounts (in the same week) between products

$\begin{array}{cccccc}\text { Product } & \begin{array}{c}\text { Pers. } \\ \text { Trans }\end{array} & \begin{array}{c}\text { Savings } \\ \text { A/C's }\end{array} & \begin{array}{c}\text { Carded } \\ \text { Term Dep }\end{array} & \begin{array}{c}\text { Noncarded } \\ \text { Term Dep }\end{array} & \begin{array}{c}\text { All } \\ \text { Retail }\end{array} \\ \text { Pers Trans } & 1.00 & 0.85 & 0.38 & 0.63 & 0.81 \\ \text { Savings A/C's } & 0.85 & 1.00 & 0.28 & 0.49 & 0.69 \\ \text { Carded T.D. } & 0.38 & 0.28 & 1.00 & 0.51 & 0.79 \\ \text { Noncarded T.D. } & 0.63 & 0.49 & 0.51 & 1.00 & 0.85 \\ \text { All Retail } & 0.81 & 0.69 & 0.79 & 0.85 & 1.00\end{array}$

TABLE 3: the correlation of the number of withdrawals and their size between products.

\begin{tabular}{|c|c|c|c|c|c|}
\hline $\begin{array}{l}\text { Product } \\
\text { no. vs size }\end{array}$ & $\begin{array}{l}\text { Pers. } \\
\text { Trans }\end{array}$ & $\begin{array}{c}\text { Savings } \\
\text { A/C's }\end{array}$ & $\begin{array}{l}\text { Carded } \\
\text { Term Dep }\end{array}$ & $\begin{array}{l}\text { Noncarded } \\
\text { Term Dep }\end{array}$ & $\begin{array}{c}\text { All } \\
\text { Retail }\end{array}$ \\
\hline Pers Trans & 0.65 & 0.50 & -0.21 & 0.41 & 0.34 \\
\hline Savings $A / C^{\prime} s$ & 0.58 & 0.13 & -0.20 & 0.14 & 0.21 \\
\hline Carded T.D. & 0.46 & 0.68 & -0.37 & 0.31 & 0.51 \\
\hline Noncarded T.D. & 0.78 & 0.60 & 0.10 & 0.51 & 0.83 \\
\hline All Retail & 0.66 & 0.44 & -0.22 & 0.37 & 0.32 \\
\hline
\end{tabular}

\subsection{Correlation between number and size of withdrawals}

Consider Table 3. The personal transactional and non-carded term deposit products show strong positive correlations between the number and size of the withdrawal. The other products do not conform to this pattern and the overall result for all products is a modest $32 \%$. Correlations of this magnitude cannot be ignored however. An assumption of independence between number and size of withdrawal is clearly not tenable. A real difficulty is determining the strength of this dependence in a crisis situation, although it may be expected to follow the worst case scenario. 


\subsection{A model of which allows for dependence}

The expected values of the mob, clip and bag are fixed by definition, that is,

$$
E\left[M_{t}\right]=1, \quad E\left[C_{t}\right]=1, \quad E\left[B_{t}\right]=1 .
$$

It follows immediately that $E\left[B_{t}\right]=E\left[M_{t}\right] \times E\left[C_{t}\right]$. However, we cannot assume that $E\left[B_{t}\right]=E\left[M_{t} \times C_{t}\right]$ unless we can show that the mob and clip are independent. We have good reason to suspect the contrary case! We may alternatively assume that some association exists. Returning to our original variables, let

$$
E\left[Z_{t}\right]=E\left[N_{t} \times Y_{t}\right]=e^{k} E\left[N_{t}\right] \times E\left[Y_{t}\right] .
$$

The relationship $Z_{t}=N_{t} \times Y_{t}$ is written in terms of the scaled variables as

$$
\bar{Z} B_{t}=\bar{N} M_{t} \times \bar{Y} C_{t},
$$

giving

$$
B_{t}=\frac{\bar{N} \bar{Y}}{\bar{Z}} M_{t} \times C_{t}
$$

We now take logarithms to obtain the new equation

$$
b_{t}=m_{t}+c_{t}-k,
$$

where

$$
b_{t}=\ln B_{t}, \quad m_{t}=\ln M_{t}, \quad c_{t}=\ln C_{t}, \quad k=\ln \frac{\bar{Z}}{\bar{N} \bar{Y}} .
$$

The value of $k$ can be positive, zero or negative. This measure of association is related to the coefficient of correlation between $N_{t}$ and $Y_{t}$ and also incorporates the effect of any skewness which may exist in either variable.

This rewritten expression might look like linear regression, but it is in fact a linear structural equation for the data that gives equal weight to the variations in number and size. 


\subsection{Degree of association}

The parameter $k$ provides a measure of the extent to which the association between size and number influences the total amount.

In terms of our expected values

$$
k=\ln \bar{Z}-\ln (\bar{N} \bar{Y}) \approx \ln E\left[N_{t} \times Y_{t}\right]-\ln \left(E\left[N_{t}\right] \times E\left[Y_{t}\right]\right) .
$$

If size and number are independent variables, then $k$ would be close to zero. Our sample weekly data retail products provides us with a range of examples:

- No association: Savings accounts $(k=0)$.

- Negative association:Carded term deposits $(k=-.019)$.

- Positive association: Personal transactional $(k=.002)$ and non carded term deposits $(k=.019)$.

This result for Savings accounts may be spurious as there is distinct evidence of a fortnightly cycle.

\subsection{Principal risk factors}

Does variation in size or number of withdrawals provide the bigger risk? We comment on each product in turn using graphical illustrations, using our limited data. Recall that the $\log$ clip and $\log$ mob are simple measures of size and number of withdrawals, and a scatter plot of these gives a sense of their relationship. It can be noted too that the scales on each graph follow naturally from our method of analysis and make comparisons easier. A wider scatter in data points in either axis direction implies a greater degree of risk associated with the measure along that axis. 


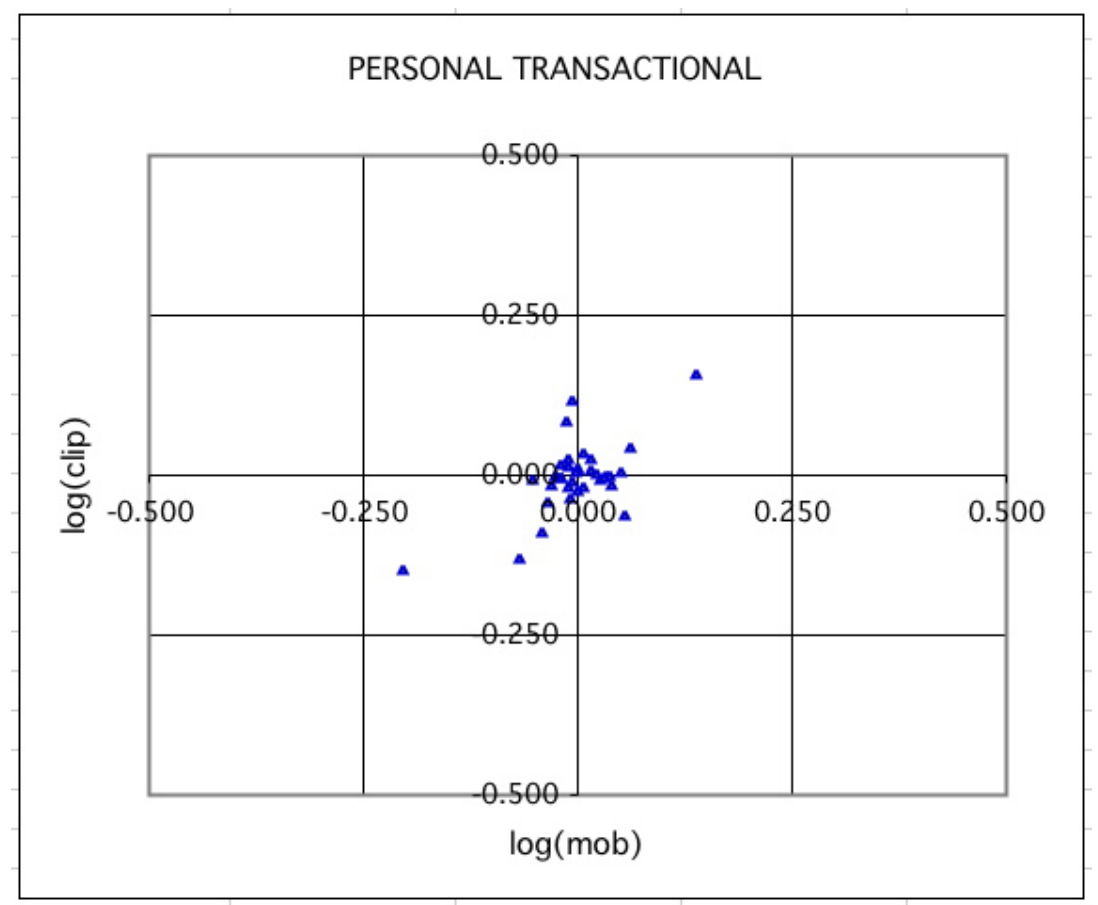

Figure 1: 


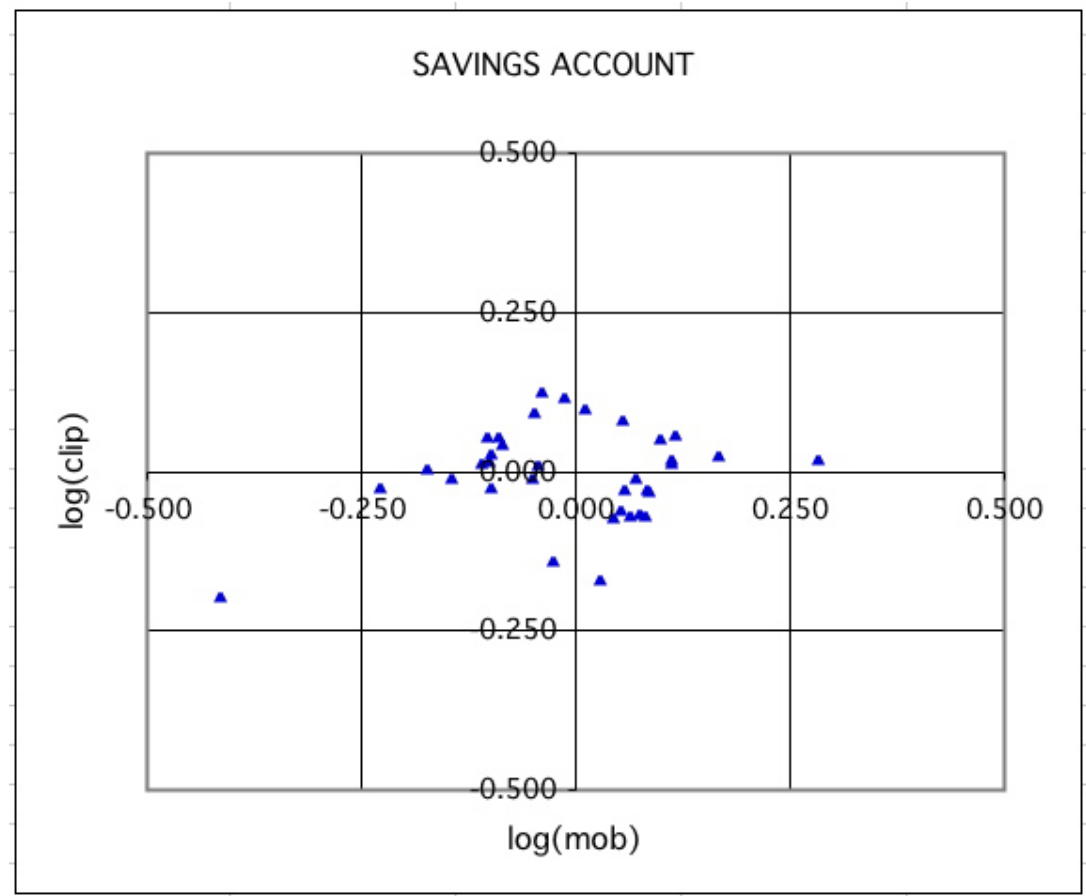

Figure 2:

The effect of the Easter holiday break on the Personal transactional product is quite pronounced. For the personal transactional product both number and size are influential (Figure 1) .

The data for the Savings account product has strong fortnightly cycle. For this product the number of transactions is more variable than the size (Figure 2) . There is a distinct lack of values close to the average which can be readily explained by the fortnightly cycle.

The time series for the carded term deposit data exhibits an intertwined pattern due to the strong negative association between number and size.

The non-carded term deposit product exhibits features that increase liq- 


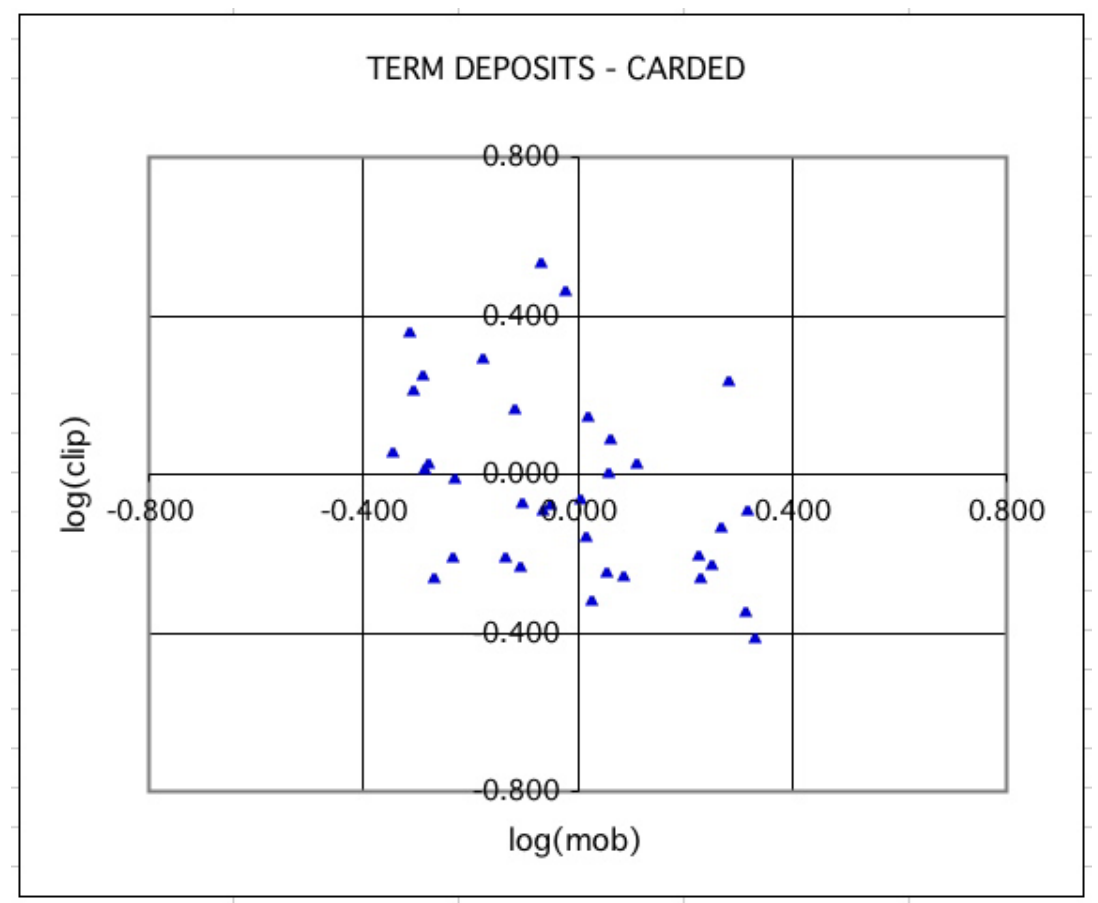

Figure 3: 


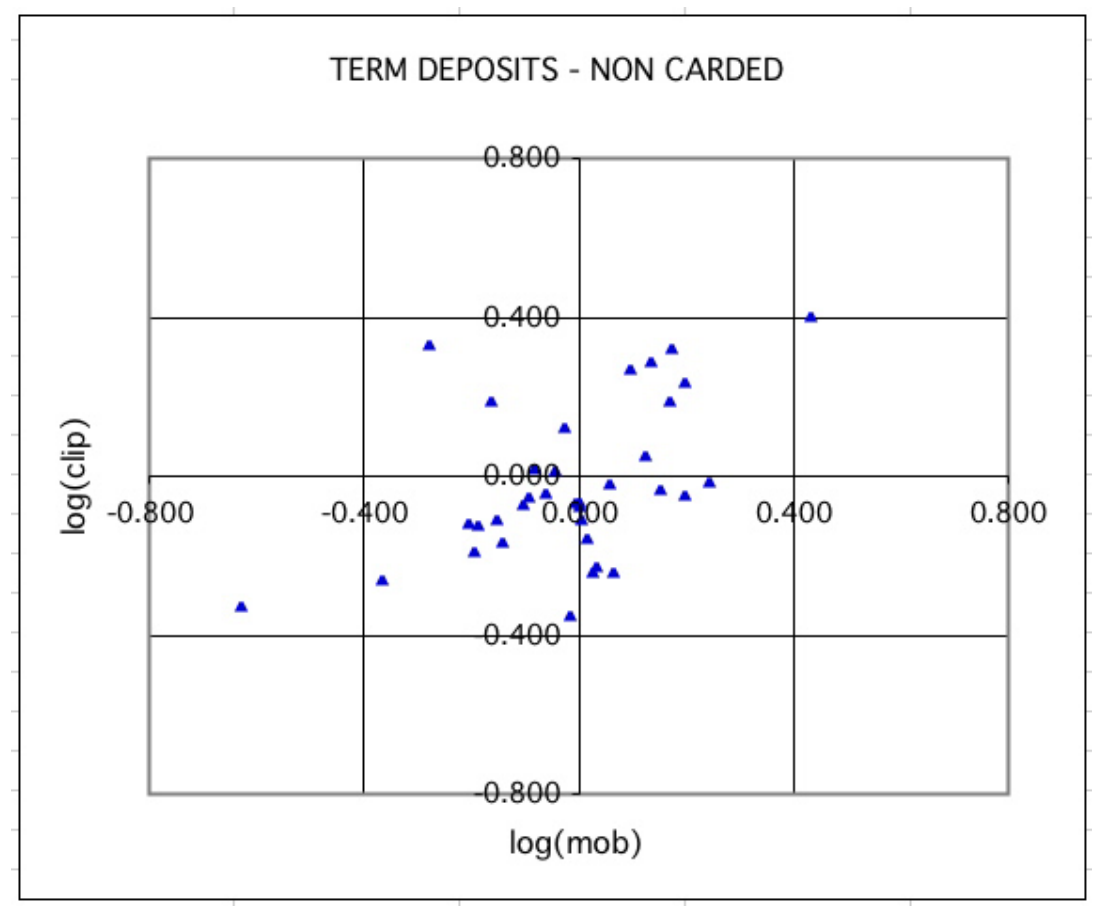

Figure 4: 
uidity risk. The size and number of withdrawals has a positive association (Figure 4) . Surprisingly, given the nature of this product, it appears that the number of withdrawals is more influential on the liquidity risk than their size!

\section{Conclusion}

This bank management should be pleased with the results for carded term deposits. The determination of the carded rates is smoothing the fluctuations in the withdrawal amounts. However the result for non-carded term deposits, often, larger deposits, must be disappointing. It seems the team of investors who operate in this market are increasing the liquidity risk of the bank. Perhaps the dealers are placing too much time watching movements in the external market and not paying enough attention to the shape of the internal book.

The structural equation developed above provides a simple inexpensive tool for supervisory control of the on-going liquidity risk of the bank. Liquidity risk can be reduced by controlling the manner in which the book is built. It is desirable that number and size of withdrawals have a negative association at each future date.

A methodology to calculate reserves to cover the liquidity risk has been demonstrated. However, more data is required before any reliance can be placed on the calculated values. Parameter estimates obtained from small samples can contain significant biases.

Acknowledgment: The authors gratefully acknowledge Ed Bosworth and Alicia Low for their assistance in providing data for the problem and useful commentary on the results. 


\section{References}

[1] Allan J. N., Booth P. M., Verrall R. J. and Walsh D. E. P., (1998), The management of Risks in Banking, British Actuarial Journal, Vol 4, Part IV, pp.707-802. C520

[2] Beard, R. E., Pentikainen, T. and Pesonen, E. (1977) Risk Theory: The Stochastic Basis of Insurance, Chapman and Hall C523

[3] Dowd, K. (1998) Beyond Value at Risk: The New Science of Risk Management Wiley. C520, C521

[4] Monkkonen, H. (2000) Managing the Spread, Risk, October pp109-112 C520

[5] Santomero, A. M. (1997) Risk Management in Banking: Practice Reviewed and Questioned. In D. Galai, D. Ruthenberg, M. Sarnat and B. Schreiber (Eds) Risk Management and Regulation in Banking Kluwer. Boston. C520 